\title{
Gestão e Formação Contínua: \\ práticas articuladas da \\ organização escolar
}

Beatriz Gomes Nadal'

\section{RESUMO}

A dinâmica da realidade social e educacional coloca cada vez mais ao professor a necessidade de uma prática pedagógica reflexiva capaz de permitir-lhe debruçar-se sobre ela a fim de compreendê-la em sua essência, captando suas contradições e limitações e, assim, transformá-la; a implementação do processo reflexivo, porém, encontra inúmeros fatores dificultadores, por conta da atual organização escolar'e mesmo da cultura existente na escola. Somadas a essas dificuldades, surge também a do gerenciamento de tais processos na organização escolar através de um esquema de gestão democrática e participativa capaz de articular conflitos e dificuldades presentes na escola e assim viabilizar práticas de formação contínua para reflexão sobre o trabalho docente e a prática escolar como um todo

A implementação da gestão democrática na organização escolar passa pela participação enquanto construção conjunta de todos os sujeitos envolvidos que por sua ação consciente buscam, na problematização e discussão de suas práticas e das práticas escolares como um todo, gerirem juntos os processos educativos. A participação na gestão democrática apresenta também como demanda o saber, o conhecer, que se constrói através dos processos de formação.

O objetivo do presente trabalho, então, é discutir o círculo de articulação que se estabelece entre gestão escolar e formação continuada de profissionais do ensino na medida em que a efetivação da formação contínua dentro do espaço escolar passa pelos processos de gestão desencadeados na escola e

\footnotetext{
'Professora colaboradora do Departamento de Métodos e Técnicas de Ensino e Supervisora Escolar da rede pública estadual.

Olhar de professor, Ponta Grossa, 3 (3):15-28, nov. 2000.
} 
que para que tais processos se efetivem de maneira democrática, com participação, faz-se necessário aos profissionais o saber que viabiliza essa participação, saber esse que também se constrói através da formação contínua. Compreende-se, assim, a gestão e a formação contínua como práticas articuladas da organização escolar.

Palavras-chave: gestão, formação, prática reflexiva

O contexto sócio-econômico, cultural e político vivenciado pelas sociedades na contemporaneidade traz consigo decorrências para as práticas escolares e, dentre elas, para as práticas de formação dos profissionais da educação, haja visto a necessidade de uma compreensão objetiva, por parte do professor, do contexto de mudanças que vivencia, assim como das interferências dessas mudanças sobre seu trabalho e a formação do aluno.

A compreensão da contemporaneidade e de suas influências exige também do professor novas formas de trabalho capazes de dar conta das novas exigências e dificuldades encontradas, o que desafia sua competência profissional, seu saber fazer. PERRENOUD (p.11, 2000), citando MEIRIEU, aponta novas competências que se colocam hoje aos professores diante da dinâmica social e educacional presente: "Prática reflexiva, profissionalização, trabalho em equipe e por projetos, autonomia e responsabilidade crescentes, pedagogias diferenciadas, centralização sobre dispositivos e sobre as situações de aprendizagem, sensibilidade à relação com o saber delineiam um roteiro para um novo ofício."

Contudo, têm sido difícil para os professores o enfrentamento desse novo contexto; muitos docentes, ao situarem-se num panorama de grandes transformações e de novas exigências, não as compreendem como também não entendem de que maneira devem reagir pessoal ou profissionalmente, caracterizando o fenômeno que ESTEVE (1995, p. 97-98) vêm denominando como mal-estar docente: "conjunto de reacções dos professores como grupo profissional desajustado devido à mudança social" ou "efeitos permanentes, de caráter negativo, que afectam a personalidade do professor como resultado das condições psicológicas e sociais em que exerce a docência, devido à mudança social acelerada".

As alternativas de enfrentamento ao processo de mal-estar docente compreendem, no contexto de açōes necessárias, ações relativas a formação de professores, programas que possibilitem ao professor o real entendimento de seu campo de trabalho e o avanço desse em direção a novas 
competências através de um processo de conhecimento que parta da prática, do "chão da escola", da realidade; programas que propiciem a formação do "professor reflexivo".

A formação do professor como prático reflexivo obedece a uma nova racionalidade, a racionalidade prática, novo paradigma de formação que respalda-se em trabalhos como os de SCHÖN, ZEICHNER E ELLIOT, entre outros, para propor novo direcionamento nas práticas formativas até hoje desenvolvidas.

As idéias de SCHÖN acerca dos diferentes níveis de conhecimento é um dos contributos basilares para o entendimento da racionalidade prática na formação de professores. $\mathrm{O}$ autor demonstra que o desenvolvimento profissional efetiva-se com recurso a três momentos de "conhecer": o conhecimento na ação, uma espécie de saber que fundamenta a atividade prática, tornando possível um "saber fazer", independentemente da existência sobre esse saber; a reflexão na ação, uma reflexão pouco rigorosa que acontece no momento da prática, quando nessa surgem situações inusitadas ou problemáticas, diante da necessidade de, momentaneamente, reagir ou reconduzir a ação em tais situações e a reflexão sobre a ação e sobre a reflexão na ação, uma reflexão posterior que visa analisar retrospectivamente a ação passada e as reflexões realizadas naquele instante, ou seja, trata-se de olhar detidamente os fatos buscando compreendê-los no contex to onde estão inseridos para, a partir de tal compreensão, estudar também possíveis alternativas de novas ações capazes de dar conta da problemática em questão.

A dinâmica ação-reflexão-ação visa superar teorias prescritivas em relação a prática para que o professor torne-se capaz de "também aprender a construir e comparar novas estratégias de acção, novas fórmulas de pesquisa, novas teorias e categorias de compreensão, novos modos de enfrentar e definir os problemas. Em conclusão, o profissional reflexivo constrói de forma idiossincrática o seu próprio conhecimento profissional (...). (GÓMES, 1992, p. 110).

Trata-se de uma busca da conquista da unidade teoria-prática, já que a teoria poderá ser construída a partir da prática, tornando a ambas críticas, coerentes e criativas através de um trabalho continuado e crescente, dando ao trabalho docente uma dimensão investigativa.

A importância do processo de reflexão prática está no resgate que dá à valorização do saber docente enquanto elemento fundamental no desenvolvimento da própria formação profissional, assim também como na formulação dos objetivos de seu trabalho e dos meios de atingi-los. Torna-se explícito o caráter participativo da formação reflexiva pois os professores tornam-se sujeitos de suas próprias práticas e da prática educativa escolar como um todo.

Outra perspectiva da 
racionalidade prática é a reflexão na prática para a reconstrução social onde a prática é tomada como prática social ética, cujos valores devem traduzir-se nos procedimentos realizados no processo ensino-aprendizagem. $O$ ensino está muito associado ao desenvolvimento da consciência dos cidadãos visando à transformação social para superação das desigualdades. O professor, "educador e ativista político", atua partindo sempre do compromisso político na formação de alunos, também conıprometidos com as questões sociais. $\grave{A}$ escola cabe, então, a tarefa de "pensar criticamente sobre a ordem social". A neutralidade da função educativa escolar, do papel do professor e até mesmo dos cursos de formação é totalmente negada, para o que se pretende, em relação ao professor,

Desarrollar su capacidad reflexiva mediante un proceso de investigación-acción sobre la propia práctica y las condiciones económicas, sociales y poíticas que rodean la intervención del docente (...). De este modo, la formación cultural, el estudio crítico del contexto y el análisis reflexivo de la propia práctica son los ejes sobre los que se asienta la formación del futuro profesor/a. (GÓMEZ, 1994, p. 424)

A transposição para a prática dos valores que a fundamentam coloca o desenvolvimento profissional docente como fator condicional ao desen- volvimento curricular. A prática, considerada como atividade ética e nãoinstrumental, assume lugar privilegiado. Para seu aprimoramento, tornase necessário, por parte de todos que nela estão envolvidos, um processo de reflexão contínua. Desse modo tomarse-á possível identificar um método adequado de ensino para situações concretas com as quais se defrontam os professores.

No processo de investigação-ação devem ser levadas em conta todas as variáveis que interferem na concretização dos valores que se pretendem desenvolver junto aos alunos, pois eles próprios também devem estar conscientes de tais variáveis. Sendo assim, a reflexão sobre a prática desenvolve-se de modo contínuo sem possuir um momento preestabelecido de finalização, pois a cada reflexão seguir-se-á uma nova ação e posterior reflexão e, assim, sucessivamente, num movimento crescente $\mathrm{e}$ espiralado.

A transformação da prática pedagógica se dá a partir da transformação dos participantes e da própria situação. Na busca de se reverem os esquemas de pensamento, de que se utiliza, e de se identificar e compreender os fatores intervenientes, termina-se modificando não só a postura daqueles que participam, mas também a própria situação.

Se transforman los participantes al desarrollar su capacidad para la discriminación y el juicio en situaciones humanas complejas, 
conflictivas, inciertas y singulares. (...)

Se transforman los participantes al verse inducidos a recomponer sus esquemas estandartizados de pensamiento, presionados por las evidências que construye el proceso creativo de interacciones que se potencian en el aula y en la escuela. (...)

Se transforma la realidad porque este proceso de interacciones innovadoras requiere nuevas condiciones sociales, nueva distribuición del poder y nuevos espacios para ir situando los retazos de nueva cultura que emergen en el aula (GÓMEZ, [994, p.426-427).

Partindo-se do princípio participativo na formação, torna-se importante que se estabeleçam, entre todos os participantes, diálogo, troca de idéias, discussões sobre pontos de vista divergentes e, também, análises a partir de teorias científicas já existentes.

Vale dizer, então, que a racionalidade prática, ao considerar a prática como fonte de conhecimento e de desenvolvimento dos profissionais da escola, propõe a a superação da fatores hoje existentes dentro das organizaçōes escolares, fatores esses que são reflexos do modelo da racionalidade técnica, como a separação e hierarquização do trabalho dentro da escola; é importante que os especialistas de ensino atuem na es- cola como facilitadores e viabilizadores do processo de investigação-ação dos professores que trabalham diretamente com os alunos.

O principal objetivo de se proporem novos rumos para a formação docente é o trabalho com a própria formação, aspecto que mais tem condições de viabilizar a alteração do quadro de insucesso escolar, motivado, muitas vezes, por realidades com as quais o professor não sabe, ainda, trabalhar, tais como o aluno multi-repetente, as dificuldades de aprendizagem, a família que não tem condições de acompanhamento e apoio ao trabalho escolar, a violência entre crianças e adolescentes. Torna-se imprescindível a construção de novas metodologias, de formas diferentes de se avaliar o processo de aprendizagem do aluno. É fundamental que o professor esteja preparado para trabalhar com as diversidades, para não apenas para instruir, mas essencialmente para formar, preparar cidadãos.

Incentivar e desenvolver uma prática reflexiva requer ainda que se tenham certos cuidados, pois alguns fatores podem obstaculizar esse processo.

É importante que, durante o processo reflexivo, se trabalhem com as teorias produzidas por pesquisadores, mas que, também, se considerem as experiências e saberes do próprio professor, evitando que a reflexão se destine somente a "vender" a ele teorias prontas. Uma reflexão efetiva deve procurar sobressair-se pela elabora- 
ção do professor, tornando-o um elemento ativo no processo.

$\mathrm{O}$ trabalho com aspectos instrumentais do ensino, durante a prática reflexiva, superará uma dimensão técnica se, ainda, finalidades e conteúdos se consistirem temas de estudo e reflexão.

Vale, também, considerar-se, durante a reflexão, todos os fatores que, direta ou indiretamente, influenciam a prática escolar e, especialmente, a prática do professor, impedindo que haja um individualismo pela desconsideração dos efeitos que os condicionantes externos exercem sobre a prática pedagógica.

Um último fator que poderá obstaculizar uma reflexão efetiva é a sua negação como prática social, o que impede os professores de, coletivamente, influenciar nas condições de trabalho, pois não ocorre o estabelecimento de relações entre a prática de cada professor, em cada escola, com a prática dos demais professores, nas demais escolas.

É necessário que haja clareza acerca de tais aspectos bem como da real função do ato reflexivo que é " (...) transformar uma situação de obscuridade, dúvida, conflito, distúrbio de algum gênero, numa situação clara, coerente, assentada, harmoniosa" (DEWEY, 1959, p. 105-106), evitando-se, assim, que a prática reflexiva se torne o fím último da prática educativa.

ZEICHNER (1993, p. 25) chama a atenção no sentido de:
(...) a reflexão poder, em certos casos, solidificar e justificar práricas de ensino prejudiciais para os alunos e minar ligações importantes entre a escola e a comunidade. Por outras palavras: por vezes, os professores reflexivos podem fazer coisas prejudiciais melhor e com mais justificaçōes. (...) Em vez de aceitarmos sem críticas tudo o que um professor diz ou faz, só porque foi produzido por um professor, temos de nos debruçarmais sobre a naturezae qualidade das reflexões dos professores e sobre o saber que produzem.

Essa ressalva visa assegurar uma prática reflexiva de qualidade. Espera-se dela que não considere tão somente as questōes intrínsecas e imediatas do trabalho pedagógico, assim como o contexto em que esse trabalho acontece. É importante, inclusive, que se efetive, enquanto prática democrática e emancipatória, que se preste à abordagem do conhecimento, incluindo-se a visão sócio-política que lhe é inerente. Por fim, é importante que a prática reflexiva se estabeleça como prática social, que os professores reflitam não isoladamente, senão coletivamente, o que, por certo, fortalecerá e enriquecerá a reflexão.

Contudo, os professores não podem passar de um extremo ao outro, considerando-se, pelo desenvolvimento de uma prática reflexiva, os únicos verdadeiros produtores de co- 
nhecimento. Todo o aporte teórico que vem sendo produzido, mesmo que por pesquisadores exteriores à escola ou à comunidade do professor, pode ser considerado e trabalhado, porquanto espera-se que se tornem "tanto consumidores críticos destas investigações como pessoas capazes de participarem na sua criação" (ZEICHNER, 1993, p. 27).

Desta forma, a escola estará continuamente preocupada em oportunizar momentos que possibilitem o pensamento reflexivo de modo que ele se torne hábito. $O$ desenvolvimento de professores numa perspectiva reflexiva elimina possíveis dicotomias entre teoria e prática, entre ensino e aprendizagem, entre professor e aluno.

Ao se afirmar a importância da reflexão na escola e, em especial, a importância da reflexão do professor como aprimoramento da prática pedagógica, tem-se a considerar que, na grande maioria das vezes, a formação acadêmica pela qual o professor passou não o preparou para a referida prática, mesmo porque a formação inicial não deve ser tomada como momento primeiro e último da formação profissional, já que inúmeros saberes produzidos a todo instante tornam a atualização imprescindível. Assim, tornam-se prementes ações que instrumentalizem o professor para continuar o desenvolvimento da formação profissional, para o que se defende uma prática formativa continuada e em serviço que articule a formação reflexiva do professor.

A formação continuada é um processo que visa capacitar ${ }^{2}$ os professores no próprio local de trabalho, a escola, cujo núcleo de ação está na prática pedagógica de cada docente e da escola como um todo coletivo.

Tal capacitação, aqui compreendida como

processo que procura desenvolver de maneira sistemática e contínua todos os recursos do homem-educador envolvido com o trabalho escolar; objetivando uma prática pedagógica competente (FUSARI e RIOS, 1995, p. 42),

pode desenvolver-se de modo sistemático a partir de cursos, grupos de estudo, projetos de investigação, encontros para trocas de experiência, discussões e demais formas de estudo, em que problemas e ações de cada professor coordenem-se com problemas e ações da escola, enquanto coletividade.

A proposta de formação de professores em serviço surgiu pela necessidade de sustentá-los no seu desenvolvimento como práticos reflexivos e pela percepção de que os treinamen-

\footnotetext{
${ }^{2}$ Por capacitaçāo se está entendendo o sentido de tomar capaz, habilitar, que o termo possui. A esse respeito veja: MARIN, Alda Junqueira. Educaçāo continuada: introduçāo a uma análise de termos e concepções. In: Cadernos CEDES $n^{\circ} 36$.
} 
$\operatorname{tos}^{3}$, modalidades de formação mais comumente oferecidas pelos sistemas de ensino, não davam conta de prepará-los nessa direção.

REALE et alii (1995), indicam algumas das principais dificuldades encontradas pelos professores em modalidades de-formação que acontecem de forma descontínua e isolada da unidade escolar. Entre elas estão: a duração dos cursos, cuja carga horária normalmente é pequena para a quantidade de informações com que se quer trabalhar; os temas trabalhados que, por destinarem-se à professores de instituições diferenciadas, nem sempre atendem às expectativas e necessidades de todos; a transposiçāo didática do conteúdo aprendido, que deve ser feita isoladamente por todo professor no retorno à sala de aula, tomando-se difícil, pois, no momento, em que as reais dificuldades irão surgir, o professor não pode contar com o apoio do profissional que trabalhou com ele durante o treinamento; a postura dos docentes, que normalmente são professores universitários e que, muitas vezes, desconhecem a realidade das escolas públicas de ensino fundamental e médio; as distorções e fragmentações ocorridas quando os treinamentos acontecem através de multiplicadores. Some-se a tudo isso o fato de que em muitos casos os treinamentos objetivam a implantação de novas propostas curriculares e, por assim dizer, supõem mudanças de atitudes que não acontecem simplesmente pela aquisição de novas informações.

A proposta de formação continuada de professores na própria unidade escolar procura sanar muitas dessas problemáticas. Ela pode ser explicitada a partir de alguns aspectos principais.

Primeiramente, é possível dizer que a prática pedagógica resgata-lhe o grau de importância, passando a eixo central dos currículos de formação de professores e o ponto de partida dele.

Sendo assim, a separação teoriaprática é negada, já que, tornando-se a prática um processo de investigação do professor, a rotina é superada por reflexões sobre as questões educativas e, passo a passo, un conhecimento idiossincrático vai-se construindo.

O pensamento prático do professor é analisado pelo todo, pois a capacidade de atuação profissional re-

\footnotetext{
${ }^{3}$ Segundo LUFT, treinar significa tornar hábil, destro para o desempenho de alguma atividade; adestrar. Na área da educaçāo esse termo é comumente utilizado para designar inúmeras modalidades de capacitação como cursos, palestras, seminários, encontros, etc. Nāo se pretende minimizar o valor de tais atividades, contudo, percebe-se que elas, exclusivamente, não dão conta das atuais necessidades sentidas pelos professores no que diz respeito a seus processos de capacitação. Maiores comentários podem ser encontrados em MARIN, Alda Junqueira. Educação continuada: introdução a uma análise de termos e concepções. In: Cadernos CEDES n ${ }^{\circ} 36$.
} 
sulta de fatores cognitivos, afetivos, explicativos e normativos.

O pensamento prático é uma atividade criativa, porque a todo momento novas realidades estão sendo criadas. É uma prática que não pode ser ensinada, senão aprendida.

A aprendizagem do pensamento prático resgata a importância do trabalho do supervisor ou tutor, visto que vai se dar através de reflexões conjuntas e recíprocas entre os dois.

A integração do conhecimento científico e a prática é uma conquista importante e facilitada através da utilização de métodos qualitativos no estudo de situações singulares de sala de aula e da formação do pensamento prático do professor.

Um último pressuposto seria a necessidade de se estimular o desenvolvimento profissional com parcerias entre as escolas e as Universidades para que formadores experientes apóiem, nas escolas, a realização de projetos educativos inovadores.

Formar professores na própria unidade escolar mediante um programa de capacitação contínua visa desencadear um programa de formação que supere as tradicionais dificuldades sentidas pelos professores nas modalidades formativas extra-escolares. Refletindo na própria escola, em conjunto com os pares, o professor será capaz de analisar-lhe a prática pedagógica a partir de referenciais teóri$\cos$ que possibilitem-lhe superar as dificuldades por meio de um processo em que ele próprio se configura como agente principal e que resulta na opção por estratégias realmente adequadas às suas necessidades.

A formação continuada de professores na escola, também, garante sintonia entre as ações dos professores, pois elas deverão sempre estar pautadas no projeto político-pedagógico da instituição, construído pelo coletivo escolar, garantindo um processo de formação construtivocolaborativo de parcerias entre todos os professores o que, pela reciprocidade das relações põe por terra, inclusive, as diferenças entre quem sabe e quem não sabe.

A autonomia do professor está no cerne da proposta de formação continuada. O professor passa a ser o principal agente da própria formação. Consequientemente, a vontade de buscar $\mathrm{e}$ o desejo de uma profissionalidade crescente são a mola propulsora do processo.

Se a falta de tradição da prática reflexiva nas escolas é um elemento que, circunstancialmente, pode dificultar que ela venha a se desenvolver, o modo como as escolas estão organizadas, principalmente as públicas (que normalmente precisam estar ajustadas a um modelo proposto pelas secretarias de educação), pode ser considerada a maior fator dificuldade para que tal práticas seja desencadeada.

A organização escolar é um tema que vem sendo bastante abordado, existindo, inclusive, autores que procuram demonstrar a similaridade entre a organização do sistema 
educativo e a organização do sistema produtivo nas indústrias ${ }^{4} \mathrm{e}$, ainda outros autores que, partindo da constatação de situaçōes problemáticas nas escolas, defendem a necessidade de se implantarem programas de busca da "Qualidade Total"s.

As organizações escolares têm uma especificidade própria, uma "cultura" que lhes é comum cujas práticas respondem, precipuamente, a necessidades, hábitos e costumes de tais instituições; sendo assim, é fundamental o cuidado ao tentar transferir análises de outras realidades para a organização escolar. Por outro lado, olhar a organização escolar "à luz" de outros enfoques, desde que se façam todas as restrições necessárias, pode trazer alguma colaboração.

As escolas são instituições de um tipo muito particular, que não podem ser pensadas como uma qualquer fábrica ou oficina: a educação não tolera a simplificação do humano (...) que a cultura da racionalidade empresarial sempre transporta. $E$, no entanto, a afirmação da especificidade radical da acção educativa não pode justificar um alheamento face a novos campos de saber e de intervenção. Mais do que nunca, os processos de mudança e de inovação educacional passam pela compreensão das instituições escolares em toda a sua complexidade técnica, científica e humana (NÓVOA, 1995, p. 16).

É o momento em que, ao pensar a organização escolar, interessa-nos particularmente refletir sobre quais as condições que a escola, da forma como está organizada, tem para desencadear um processo de formação de professores em serviço o qual colabore na efetivação de práticas pedagógicas reflexivas.

Nas organizações escolares temos, hoje, uma gama de fatores que influenciam negativamente o trabalho escolar: professores com carga-horária excessiva de trabalho, atuando em duas, três ou mais escolas, sem horário remunerado para formação em serviço, sem fixação nas escolas, gerando rotatividade a cada ano letivo, escolas sem o espaço físico adequado para o trabalho docente, ausência de professores ou supervisores que atuem como "tutores" dos demais professores no processo de reflexão sobre a prática o que gera, inclusive, falta de articulação dos professores em coletividade para que discutam os problemas da prática escolar.

Ao se analisar os fatores que obstaculizam a formação reflexiva de professores em serviço é preciso considerar que muitos deles são decorrências das políticas educacionais de forma mais ampla, são fruto de deci-

"Citamos, por exemplo, o artigo "As organizações escolares em análise, de Luiz Carlos de Freitas.

${ }^{5}$ Citamos como exemplo a obra Pedagogia da Qualidade Total, de Cosete Ramos. 
sões e determinações que partem de fora da escola, o que torna o trabalho com a organização escolar ainda mais exigente, pois trata-se de buscar nichos de articulação, de criativamente encontrar espaços e novas formas de trabalhar com condições que são, inicialmente, desfavoráveis. Essa compreensão estabelece uma aproximação profunda entre a formação docente e a gestão escolar pois, partindo da meta de formação de professores, torna-se necessário um processo de gestão que busque, trabalhando com as diversidades da organização escolar, alcançar a meta estabelecida. Na realidade, os espaços de aproximação não se dão apenas na escola, mas também no contexto educacional enquanto estrutura macro, tal como afirma FERREIRA (1998, p. 97):

Os nexos entre a administração da educação, as políticas educacionais e a formação de profissionais da educação são de primeira grandeza. Entendendo a administração como uma prática social de apoio à prática educativa, a política como fixação de valores constituindo declarações operacionais e intencionais (...), a formação de profissionais para o exercício desta prática competente e reflexiva é uma exigência inquestionável.

Assim, ao se discutir a gestão escolar sintonizada e comprometida com a formação dos professores, estamos acreditando na gestão democrática como modalidade de gestão capaz de dar conta da gama de novos desafios:

A gestão democrática deve estar impregnada por uma certa atmosfera que se respira na escola, na circulação das informações, na divisão do trabalho, no estabelecimento do calendário escolar, na distribuição de aulas, no processo de elaboração ou de criação de novos cursos ou de novas disciplinas, na formação de grupos de trabalho, na capacitação dos recursos humanos etc.

A gestão democrática é, portanto, atitude e método. A atitude democrática é necessária, mas não é suficiente. Precisamos de métodos democráticos de efetivo exercício da democracia. Ela também é um aprendizado, demanda tempo, atenção e trabalho. (GADOTTI, 1980, p.4)

A gestão democrática na escola é processo fundamental para a formação de professores e está a ele diretamente ligado. É importante no trabalho com a dinâmica organizacional da escola a participação de todos na discussão acerca dos problemas e dificuldades que se apresentam, do conhecimento efetivo da realidade, da elaboração de propostas de enfrentamento, pois na medida em que todos se envolvem o comprometimento com a busca de soluções possíveis toma-se um comprometimento coletivo, o que, inclusive, termina por tornar o trabalho mais fecundo e criativo; ou seja, as dificuldades para o 
desenvolvimento da formação continuada e reflexiva dos professores diante da problemática da organização escolar existente passam a ser metas a serem enfrentadas pelo coletivo.

Ampliando-se a discussão, percebemos, então, que a própria gestão democrática implica em formação docente para sua realização, pois segundo BARROSO (2000, p. 30):

A construção da autonomia enquanto mudança organizacional exige que os seus membros aumentem o seu conhecimento sobre os seus modos de funcionamento $e$ sobre as regras e estruturas que a governam. Esta aprendizagem organizacional (da e pela organização) constitui um instrumento necessário para que os actores de uma organização conheçam o seu próprio campo de autonomia e o modo como está estruturado, condição para fazer das "autonomias individuais", "autonomias colectivas".

O exercício da participação na gestão do processo de formação docente passa pela própria formação como fator de viabilização de tal participação. São eixos de ligação extrema, pois é a própria formação quem dá condições para que os professores saibam e exerçam a participação no processo de gestão democrática, ao mesmo tempo em que tal processo de gestão é fundamental para que a formação reflexiva dos professores configure-se como formação dos professores em coletividade buscando, in- clusive, sua articulação diante das dificuldades hoje existentes nas organizaçōes escolares. Compreende-se, assim, a gestão e a formação contínua como práticas articuladas da organização escolar.

\section{REFERÊNCIAS BIBLIOGRÁFICAS}

1 BARROSO, João. O reforço da autonomia das escolas e a flexibilização da gestão escolar em Portugal. In: FERREIRA, Naura S. C. (org) Gestão da educação: atuais tendências, novos desafios. São Paulo, Cortez, 1998.

2 BASTOS, João Baptista.(org) Gestão democrática. Rio de Janeiro, DP\&A, 2000.

3 CADERNOS CEDES. São Paulo: Cortez, n 36, 1995.

4 DEWEY, John. Como pensamos: como se relaciona o pensamento reflexivo com o processo educativo: una reexposição. 3. ed. São Paulo: Companhia Editora Nacional, 1958.

5 ELliOTT, John. El cambio educativo desde la investigación-acción. Madrid: Morata, 1991.

6 FALCÃO FILHO, José Leão M. Exercícios de direção. AMAE Educando. Belo Horizonte. $\mathbf{n}$. 223 , p. $12-16$.

7 FERREIRA, Naura S. C. A gestão da educação e as políticas de formação de profissionais da educação: desafios e compromissos. 
In: FERREIRA, Naura S. C. (org) Gestão da educação: atuais tendências, novos desafios. São Paulo, Cortez, 1998.

8 FUSARI, José C., RIOS, Terezinha Azerêdo. Formação continuada dos profissionais do ensino. Cadernos CEDES. São Paulo, $\mathbf{n}^{\circ}$ 36,p. 37-45, 1995.

9 GADOTTI, Moacir. Organização do trabalho na escola: alguns pressupostos. São Paulo: Ática, 1993.

10 __ Educação e poder: introdução à pedagogia do conflito. São Paulo: Cortez, 1980.

11 GADOTTI, Moacir. ROMÃO, José E. Autonomia da escola: princípios e propostas. São Paulo: Cortez, 1997.

12 GERALDI, Corinta Maria. FIORENTINI, Dario. PEREIRA, Elisabete (orgs.). Cartografias do trabalho docente: professor(a)-pesquisador(a). Campinas: Mercado de Letras: Associação de Leitura do Brasil, 1998.

13 GÓMEZ, Angel Pérez. La función y formación del profesor/a en la enseñanza para la comprensión. Diferentes perspectivas. In: SACRISTÁN, J. Gimeno. GÓMEZ, A. I. Pérez. Comprender y transformar la enseñanza. 3. ed. Madrid: Morata, 1994.

14 Las funciones sociales de la escuela: de la reproducción a la reconstrucción crítica del conocimento y la experiencia. In: SACRISTÁN, J. Gimeno. GÓMEZ, A. I. Pérez. Comprender y transformar la enseñanza. 3. ed. Madrid: Morata, 1994.

15 _. O pensamento prático do professor - a formação do professor como profissional reflexivo. In: NÓVOA, António (coord.) Os professores e sua formação. Lisboa: Publicações Dom Quixote/Instituto de Inovação Educacional, 1992.

16 NÓVOA, António (coord.). As organizações escolares em análise. 2. ed. Lisboa: Publicações Dom Quixote/Instituto de Inovação Cultural, 1995.

17 __. (org.) Os professores e sua formação . 2. ed. Lisboa: Publicações Dom Quixote/Instituto de Inovação Cultural, 1995. 18 __ (org.) Profissão professor.

2. ed. Porto: Porto Editora, 1995. 19 PERRENOUD, Philippe. Dez novas competências para ensinar. Porto Alegre, Artes Médicas Sul, 2000.

20 - Práticas pedagógicas, profissão docente e formação de professores: perspectivas sociológicas. Lisboa: Publicações Dom Quixote/ Instituto de Inovação Cultural, 1993.

21 REALE, Aline $M$ de $M$. R. et alii. O desenvolvimento de um modelo "construtivocolaborativo" de formação continuada centrado na esco- 
la: relato de experiência. Cadernos CEDES. São Paulo: $n^{\circ}$ 36, p. 65-76, 1995.

22 SACRISTÁN, J. Gimeno. GÓMEZ,

A. I. Pérez. Comprender y transformar la enseñanza. 3 .

ed. Madrid: Morata, 1994.

23 ZEICHNER, Kenneth M. A formação reflexiva de professores: idéias e práticas. Lisboa: EDUCA, 1993. 